Article

\title{
Effects of Short-Chain $n$-Alcohols on the Properties of Asphaltenes at Toluene/Air and Toluene/Water Interfaces
}

\author{
Raphael G. Martins, Lilian S. Martins and Ronaldo G. Santos * \\ Department of Chemical Engineering, Centro Universitário FEI, Av. Humberto de Alencar Castelo Branco, 3972, \\ São Paulo CEP 09850-901, Brazil; raphaelgraciuti@hotmail.com (R.G.M.); lilian_smartins@yahoo.com.br (L.S.M.) \\ * Correspondence: rgsantos@fei.edu.br; Tel.: +55-11-4353-2900
}

Received: 5 March 2018; Accepted: 21 March 2018; Published: 23 March 2018

check for updates

\begin{abstract}
Crude oil asphaltenes contain a wide series of chemical species, which includes the most polar compounds and interfacially active agents from the petroleum. Asphaltenes have been considered to be implicated in foam and emulsion formation during the petroleum recovery and production process. In this work, the interfacial activity of organic solutions containing asphaltene and $n$-alcohols was investigated. Asphaltene extraction from a $28^{\circ}$ API crude oil produced $2.5 \mathrm{wt} \%$ of $n$-pentane precipitated asphaltene (C5I). Dynamic surface and interfacial tensions of asphaltene solutions were assessed by the pendant drop method. Asphaltene films were evaluated at the air-water interface using a Langmuir trough. Results were expressed by means of the interfacial tension time-dependence. Interfacial tension measurements showed alcohols reduce the toluene/water interfacial tension of asphaltene solutions. The interfacial tension was reduced from $23 \mathrm{mN} / \mathrm{m}$ to $15.5 \mathrm{mN} / \mathrm{m}$ for a $2 \mathrm{~g} / \mathrm{L}$ solution of asphaltene plus $n$-butanol. Higher asphaltene concentrations did not affect the toluene/air surface tension. The effects of $n$-alcohols on the asphaltene surface activity was dependent on the asphaltene aggregation state. $n$-Alcohols modify the asphaltene film elasticity and the film phase behavior.
\end{abstract}

Keywords: asphaltene; surface and interfacial tension; alcohols; monolayer; petroleum

\section{Introduction}

Crude oil asphaltenes comprise higher molecular weight polar components that exhibit interfacial activity. Asphaltenes are defined as a solubility class, containing a wide series of chemical species. They constitute the crude oil fraction that is insoluble in low boiling point $n$-alkanes and soluble in toluene, benzene, carbon disulfide, chloroform and other chlorinated hydrocarbon solvents [1]. Strictly, asphaltenes are considered insoluble in $n$-pentane or $n$-heptane and soluble in toluene or benzene. These fractions are commonly abbreviated as C5I and C7I, respectively, according to the precipitant utilized in the extraction [2].

The asphaltene content in the crude oils depends mainly on the nature of the oil. Unconventional (e.g., heavy and extra-heavy) oils usually contain more asphaltene than conventional oils, which directly impacts on the oil recovery, transport and refining processes [3]. Asphaltenes contain polar and nonpolar chemical functionalities, which produce amphiphilic characteristics in solution $[4,5]$. The asphaltene amphiphilic character gives rise to the colloidal properties, such as the ability to reduce surface tension [1,6,7]. The colloidal aspects of asphaltenes have been studied for a long time [2] because of their impact on emulsion and foam stabilization, wettability alteration, pipeline blockage, damage of reservoir-rock formation and many other impairments.

In solution, asphaltenes exhibit interfacial phenomena that include adsorption and self-association. These phenomena lead to aggregation, flocculation and lastly solid deposition. The formation of 
asphaltene deposits is a major concern because asphaltene deposition impairs oil recovery and production [2,3]. Deposition of asphaltene can result in the reduction of reservoir-rock permeability and a decrease of the effective pipe diameter, restricting the oil flow.

Despite the assortment of techniques available to avoid asphaltene deposit formation, the addition of dispersants and inhibitors has been preferred because of their effectiveness and low cost $[8,9]$. The effect of additives on the inhibition of asphaltene precipitation has been investigated [10]. The result showed that ethoxylated nonylphenol and hexadecyl trimethyl ammonium bromide exhibit a positive performance.

Asphaltenes contribute to the formation and stabilization of crude oil emulsions. An interfacial film containing asphaltenes and other petroleum components supports water droplet dispersion into the continuous phase $[11,12]$. Oil-in-water $(\mathrm{o} / \mathrm{w})$ emulsions are pointed out as an emergent technology for moving viscous oils. Heavy oil emulsification can lead to the viscosity decreasing enough to allow a feasible pipeline flow $[13,14]$. Crude oil emulsions are complex systems containing many chemical structures. Alcohols and electrolytes are recognized additives that modify oil emulsion properties [15]. $n$-Alcohols have been found to be effective co-surfactants in crude oil-in-water emulsions [16]. Short-chain alcohols improve oil-in-water emulsion stability [17]. In addition, the emulsion-stabilizing effect is stressed by increasing the alkyl chain size of the alcohol [18]. This fact is related to the decrease in alcohol solubility in the aqueous phase caused by the alkyl chain length increasing.

Recent work has demonstrated that emulsions containing conventional ethoxylated surfactants and short-chain alcohols present singular properties [11,14]. The authors have shown the occurrence of phase segregation phenomena and the formation of a fluid layer of low viscosity - known as the oil-depleted layer-during stationary rheological flow. As a consequence, the oil flow as $\mathrm{o} / \mathrm{w}$ emulsions has been described as lubricated flow or slippage. The rheological behavior of the emulsions was described as markedly shear-thinning [14]. Both phase segregation and shear thinning phenomena are supposedly related to the formation of multicomponent interfacial films, which would influence the resistance and the deformability of the dispersed droplet interfaces.

In this work, the effects of the addition of linear alcohols on the interfacial behavior of asphaltenes at toluene/air and toluene/water interfaces has been investigated by means of surface tension and surface pressure measurements. $n$-Alcohols containing 4-8 carbons were blended with petroleum $n$-pentane-precipitated asphaltenes. Surface and interfacial tension were assessed by the pendant drop method. In addition, asphaltenes were spread on the air-water surface to build mixed monolayers with $n$-alcohols.

\section{Materials and Methods}

\subsection{Materials}

This study used samples of a Brazilian light oil $\left(28^{\circ} \mathrm{API}\right)$ provided as a kind gift by Petrobras. Chemicals were toluene (99.8\%), n-pentane (>99\%), n-butanol (>99\%), $n$-hexanol (>99\%) and $n$-octanol ( $>99 \%$ ), purchased from Sigma-Aldrich. Ethoxylated nonylphenol (ULTRANEX) with 10 ethylene oxide units was provided by Oxiteno (Mauá, Brazil) and used as received. Deionized and double-distilled water was used throughout.

\subsection{Methods}

\subsubsection{Crude Oil Fractionation}

Asphaltene extraction from crude oil was performed according to its solubility. The $n$-pentaneinsoluble asphaltene (C5I) fraction was removed from the crude oil through a modified IP-143/89 methodology. Briefly, $800 \mathrm{~mL}$ of flocculant ( $n$-pentane) was mixed with $20 \mathrm{~g}$ of crude oil in a closed vessel. The mixture was stirred for $24 \mathrm{~h}$ at room temperature $\left(20 \pm 1{ }^{\circ} \mathrm{C}\right)$. The solid precipitated was removed by vacuum filtration using a Whatman \#42 filter paper (Sigma-Aldrich Corp., 
St. Louis, MO, USA) and the soluble phase (deasphaltened oil) was collected. The asphaltenes were separated from the solid precipitate by means of a Soxhlet extraction using $n$-pentane. This procedure was continued until the draining solvent was colorless. The asphaltene was dried before further use.

\subsubsection{Surface and Interfacial Tension Measurement}

The surface tension (ST) and interfacial tension (IFT) were each measured by the pendant drop method using a Theta Lite optical tensiometer (Biolin Scientific, Gothenburg, Sweden). The equipment captures successive images of the droplet through a charge-coupled device (CCD) camera to analyze shape parameters. The evaluation system applies the axisymmetric drop shape analysis (ADSA) method along with the Laplace equation to determine the tension. Data analyses were supported by OneAttension software, (version 2, 2015-02-04, Gothenburg, Sweden). The equilibrium state was defined through the surface and interfacial tension as a function of time. ST and IFT measurements were carried out at $20^{\circ} \mathrm{C}\left( \pm 1^{\circ} \mathrm{C}\right)$.

\subsubsection{Surface Pressure Measurement}

The surface pressure of spread films on water was evaluated using a Langmuir trough (Biolin Scientific, Sweden) with an area of $242.25 \mathrm{~cm}^{2}(32.3 \mathrm{~cm} \times 7.5 \mathrm{~cm})$. The trough was equipped with two mobile barriers made from hydrophilic Delrin. Deionized and double-distilled water was used as the subphase, which was kept constant at $20^{\circ} \mathrm{C}$. The temperature was controlled within $0.1{ }^{\circ} \mathrm{C}$ by a refrigerated circulator (Julabo, Germany). Asphaltenes were spread on the air-water surface from fresh dichloromethane solutions with a concentration of $2 \mathrm{~g} \cdot \mathrm{L}^{-1}$. A volume of $50 \mu \mathrm{L}$ of C5I asphaltene solution was used. The solvent was allowed to evaporate for at least $15 \mathrm{~min}$ before starting the measurements. The barrier speed was maintained constant at $10 \mathrm{~mm} \mathrm{~min}^{-1}$. The surface pressure was zeroed before asphaltene spreading. Tests carried out before the asphaltene addition on the aqueous phase always displayed surface pressure changes lower than $0.05 \mathrm{mN} \mathrm{m}^{-1}$.

\section{Results}

\subsection{Asphaltene Interfacial Behavior}

Addition of $n$-pentane to $20 \mathrm{~g}$ of oil yields $0.7377 \mathrm{~g}$ of solid precipitate. The solid Soxhlet cleaning procedure yields $0.5003 \mathrm{~g}$ of C5I asphaltenes, corresponding to a content of $2.5 \mathrm{wt} \%$ of asphaltene in the crude oil. The weight difference implies $32 \mathrm{wt} \%$ of impurities present in the precipitated solid. The impurities are suggested to be comprised of other oil fractions (saturates, resin and aromatics) precipitated as asphaltene mixed clusters. The C5I asphaltenes were dissolved in toluene at concentrations ranging from $1 \mathrm{~g} / \mathrm{L}$ to $10 \mathrm{~g} / \mathrm{L}$. The surface and interfacial tension of asphaltene solutions as a function of time are shown in Figure 1. ST data are shown in Figure 1a for asphaltene concentrations up to $3 \mathrm{~g} / \mathrm{L}$. Surprisingly, surface tension measurements produced a dispersion of data, regardless of the asphaltene concentration. The surface tension of 4-10 g/L solutions displayed similar behavior. At $10 \mathrm{~g} / \mathrm{L}$, the surface tension was $28.5 \pm 0.2 \mathrm{mN} / \mathrm{m}$, for instance. This result shows that asphaltenes do not exhibit significant surface activity in the air-water interface for the concentration range studied.

Interfacial tension data are presented in Figure $1 \mathrm{~b}$. The results indicate that increasing the asphaltene concentration leads to a continuous reduction of the interfacial tension. The equilibrium interfacial tension was evaluated at $900 \mathrm{~s}$. The maximum IFT reduction was achieved at a concentration of $5 \mathrm{~g} / \mathrm{L}$, which means an IFT change from $33.5 \mathrm{mN} / \mathrm{m}$ for pure toluene to $20.0 \mathrm{mN} / \mathrm{m}$ for a $5 \mathrm{~g} / \mathrm{L}$ asphaltene solution. No further decline of the interfacial tension is seen at concentrations greater than $5 \mathrm{~g} / \mathrm{L}$. 


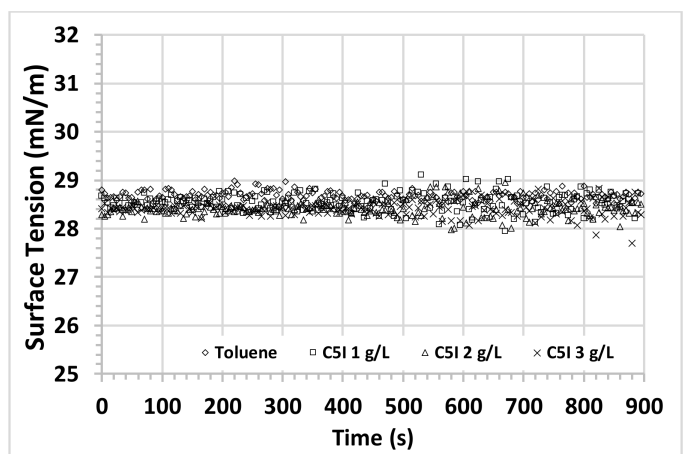

(a)

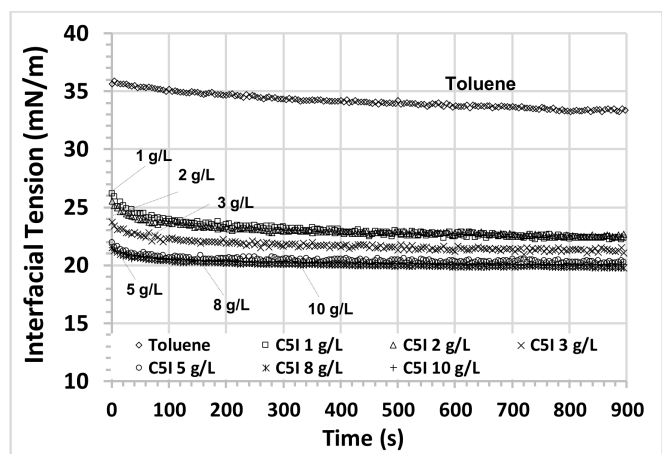

(b)

Figure 1. Asphaltene interfacial activity: (a) Surface tension and (b) interfacial tension of C5I in toluene solutions as a function of time.

The equilibrium surface and interfacial tensions were plotted against the solution concentration in order to determine the Critical Aggregation Concentration (CAC) of asphaltene for the toluene-water system. Results are shown in Figure 2. Figure 2a highlights the constant surface tension with increasing asphaltene concentration. This means that no interfacial effects take place at the air-water interface. Figure $2 \mathrm{~b}$ displays an exponential-type decline of the interfacial tension with increasing concentration. The asphaltene CAC was found at approximately $1.4 \mathrm{~g} / \mathrm{L}$.

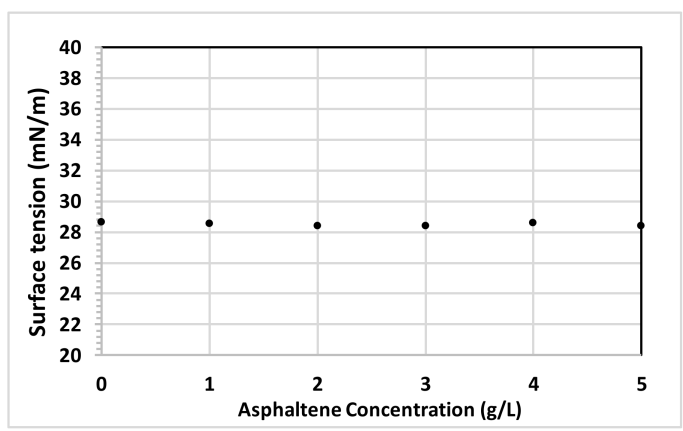

(a)

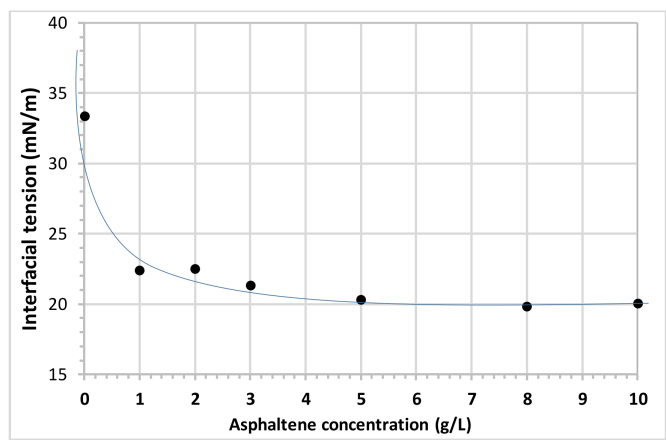

(b)

Figure 2. (a) Surface tension and (b) interfacial tension as a function of asphaltene-in-toluene solution concentration.

Figures 1 and 2 describe asphaltene colloidal behavior. Asphaltenes are denoted as single monomers at very low concentrations. As the concentration increases, the monomers adsorb at the interface as stacks, reducing the interfacial tension, as indicated by the reference [2]. At concentrations higher than the CAC, asphaltene is represented as colloidal aggregates.

\subsection{Interfacial Behavior for Asphaltene + Alcohol Systems}

$n$-Alcohols were mixed with C5I asphaltenes to evaluate the mixture surface and interfacial tensions. $n$-Butanol, $n$-hexanol and $n$-octanol were mixed with toluene to produce a solvent containing $90 \mathrm{vol} \%$ toluene and $10 \mathrm{vol} \%$ alcohol. C5I asphaltene was then dissolved in the toluene/alcohol solvent mixtures at concentrations of $0.5 \mathrm{~g} / \mathrm{L}$ and $2 \mathrm{~g} / \mathrm{L}$, in order to evaluate the asphaltene interfacial behavior at concentrations above and below the CAC.

Figure 3 displays the surface and interfacial tension of C5I solutions in a solvent composed of $90 \%$ toluene and 10\% n-butanol. Figure 3a shows that the surface tension of asphaltene solutions was approximately constant over the experimental timescale for this mixture-similar to the pure toluene solutions, although the interfacial tension increases over time (Figure 3b). The time-dependence 
of the interfacial tension is related to the surface saturation kinetics. The surface saturation rate is governed mainly by two processes: (1) molecular diffusion to the interface and (2) the reorientation of molecules at the interface $[19,20]$. In addition, $n$-butanol makes the solvent more polar, increasing the water-solvent mutual solubility. As a result, the interfacial tension of the toluene/n-butanol mixture against water increases to reach the equilibrium at about $23 \mathrm{mN} / \mathrm{m}$. At a concentration below the $\mathrm{CAC}$, asphaltene did not affect the interfacial tension, exhibiting a behavior similar to the pure solvent. Above the CAC, the solvent interfacial tension was reduced from $23 \mathrm{mN} / \mathrm{m}$ to about $15.5 \mathrm{mN} / \mathrm{m}$ at equilibrium, indicating asphaltene interfacial activity.

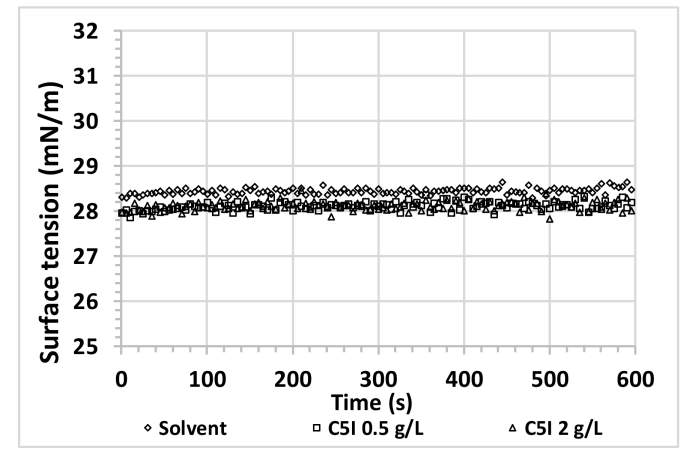

(a)

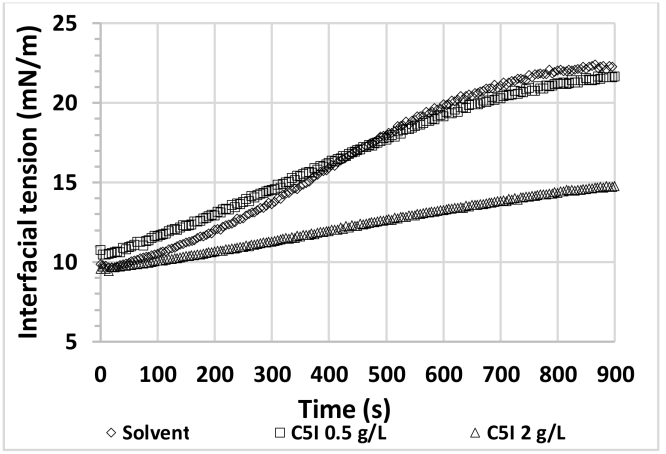

(b)

Figure 3. (a) Surface tension and (b) interfacial tension as a function of time for C5I in 9:1 v/v toluene/n-butanol solutions.

The surface and interfacial tensions for asphaltene solutions in a 9:1 $v / v$ toluene/n-hexanol mixture as a function of time are presented in Figure 4. Again, Figure 4a shows behavior analogous to that found in $n$-hexanol, remaining approximately constant over time and across concentration variations. At the oil-water interface, no abrupt change in the solvent interfacial tension was observed, even at a concentration higher than the CAC, as illustrated by Figure $4 \mathrm{~b}$. Increasing asphaltene concentration results in a small increase in the interfacial tension. This behavior is suggested to be related to the minor effect of $n$-hexanol on the asphaltene solubility in comparison to $n$-butanol. Besides, the $n$-hexanol solubility in water is much lower than the $n$-butanol solubility.

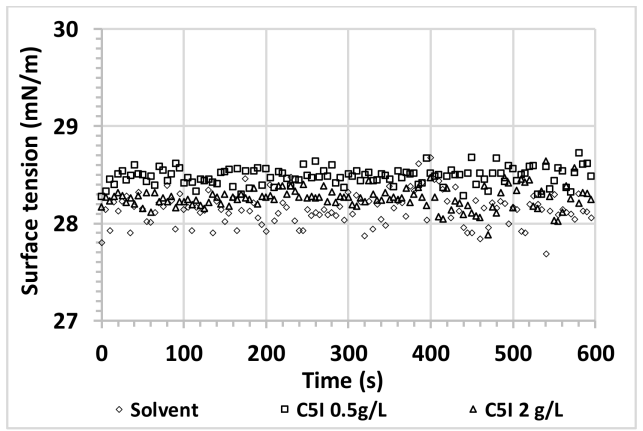

(a)

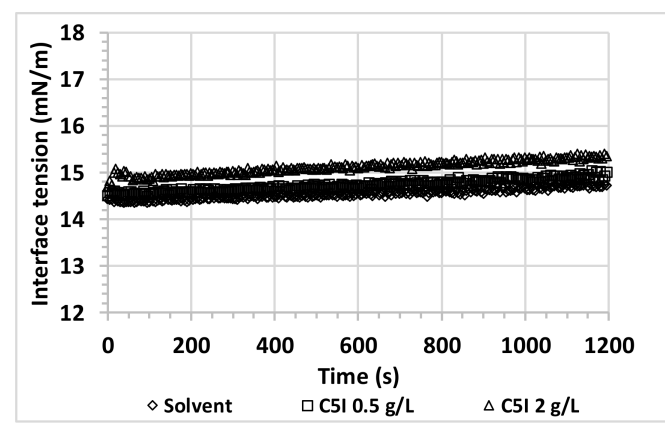

(b)

Figure 4. (a) Surface tension and (b) interfacial tension as a function of time for C5I in 9:1 v/v toluene/ $n$-hexanol solutions.

Figure 5 illustrates the effects of $n$-octanol on the surface and interfacial tension of asphaltene solutions. The surface tension was about constant over time and with concentration, in agreement with previous results for $n$-butanol and $n$-hexanol (Figure 5a). In the presence of $n$-octanol, the interfacial tension is slightly reduced over time. The IFT curves for the solvent and $0.5 \mathrm{~g} / \mathrm{L} \mathrm{C5I}$ solution are nearly 
coincident with time, indicating that at concentrations below the $\mathrm{CAC}$, asphaltene demonstrated no effective interfacial activity. For a concentration above the CAC, the IFT is slightly below the solvent IFT. In this case, the diffusion of $n$-octanol molecules must affect the IFT because of the difference in molecular weight.

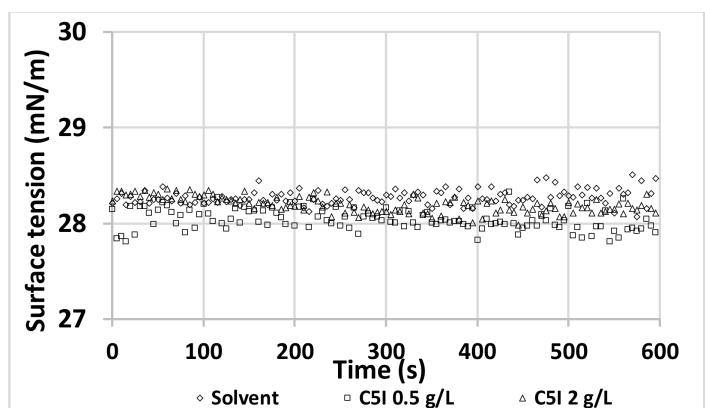

(a)

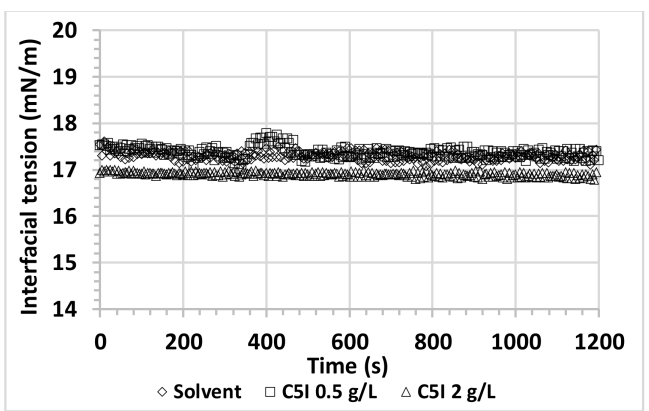

(b)

Figure 5. (a) Surface tension and (b) interfacial tension as a function of time for C5I in 9:1 v/v toluene/ $n$-octanol solutions.

Surfactants are known to reduce the interfacial tension of oil-water systems (Rudin and Wasan, 1992). Nonylphenol ethoxylated surfactants (NPE) are widely used in crude oil emulsion formulations. A series of tests was therefore carried out to evaluate the combined effects of C5I asphaltene and a conventional surfactant. The surfactant was a NPE with 10 ethylene oxide groups, corresponding to an HLB of 13.3. The asphaltene (C5I) and the surfactant (NPE) were mixed in different proportions and then the C5I + NPE blend was dissolved in the solvent to produce a total concentration of $2 \mathrm{~g} / \mathrm{L}$. The solvents were 9:1 $v / v$ toluene/alcohol mixtures, as above. The results of interfacial tension measurements are present in Figure 6. The equilibrium interfacial tension was evaluated at $600 \mathrm{~s}$, with the exception of $\mathrm{C} 5 \mathrm{I}$ in toluene $/ n$-butanol, for which equilibrium was reached at $900 \mathrm{~s}$. The data highlight the influence of the solvent in the asphaltene/surfactant interfacial activity. The greater difference between NPE and C5I interfacial tension was found in toluene, where the IFT was $9 \mathrm{mN} / \mathrm{m}$ for NPE and $22.5 \mathrm{mN} / \mathrm{m}$ for C5I. For toluene/alcohol mixtures, the interfacial tension was found to be intermediate. The interfacial tension increases with increasing alcohol chain length. The results in Figure 6 underline the variation of the C5I interfacial behavior according to the solvent properties. The addition of alcohol to toluene reduces the interfacial tension. The higher the alcohol polarity, the lower the interfacial tension.

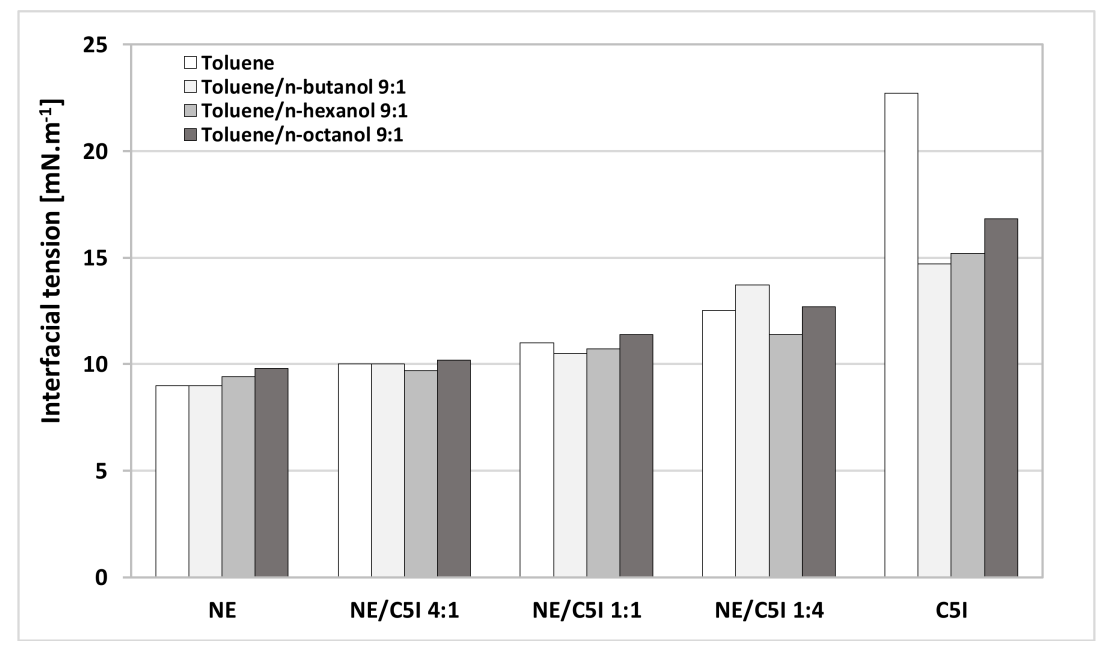

Figure 6. Interfacial tension of C5I + NPE mixtures in different solvents. 


\subsection{Langmuir Films Containing Asphaltenes and n-Alcohols}

Langmuir isotherms resulting from surface pressure measurements for asphaltene films performed at $20^{\circ} \mathrm{C}$ are shown in Figure 7 in terms of the surface pressure-surface area $(\pi$-A) isotherms. The films were spread at the air-water surface. $n$-Alcohols were added into $2 \mathrm{~g} / \mathrm{L} \mathrm{C5I}$ solutions. The alcohol amounts were: $n$-butanol $=9.5 \times 10^{-5} \mathrm{~mol}(0.007 \mathrm{~g}) ; n$-hexanol $=8.5 \times 10^{-5} \mathrm{~mol}(0.0087 \mathrm{~g})$; $n$-octanol $=9.1 \times 10^{-5} \mathrm{~mol}(0.012 \mathrm{~g})$. The respective resulting C5I:alcohol mass ratios are 70, 87 and 120 .

The C5I isotherm shape (see Figure 7) is analogous to asphaltene isotherms previously reported by other authors [11,21-23]. Initially, the isotherm shows a short region indicative of the phase transition from gaseous to liquid expanded states, which is usual for weakly interacting molecules. The film compression produced an expanded liquid region up to about $180 \mathrm{~cm}^{2}$, at a surface pressure of $18 \mathrm{mN} / \mathrm{m}$. From this point, a second phase transition occurs and the isotherm exhibits behavior corresponding to the coexistence of a two-phase region, containing both an expanded liquid phase and a condensed liquid phase. Further compression up to $30 \mathrm{~cm}^{2}$ leads the system to a third phase transition, from which only a condensed liquid state is present. At this point, the surface pressure reaches $41 \mathrm{mN} / \mathrm{m}$. The surface pressure reached $46 \mathrm{mN} / \mathrm{m}$ at the minimum area. High surface pressure indicates low film compressibility. Film collapse, which is characterized by an abrupt reduction of surface pressure, was not observed. This fact indicates substantial film elasticity.

The interfacial behavior of C5I:alcohol mixed films was dissimilar to the films containing only asphaltenes. First, the gaseous film region was broader for monolayers containing $n$-alcohols. Second, the film elasticity is altered by the addition of alcohols. The presence of $n$-butanol initially leads to a characteristic gaseous film and a smooth phase transition. Films containing $n$-hexanol exhibit only one phase transition, corresponding to the gas-liquid expanded transition. The C5I:n-hexanol film displayed a large expanded liquid region, starting with very low surface pressure $(5 \mathrm{mN} / \mathrm{m})$. Isotherms obtained from C5I:n-octanol films exhibited well-defined phase regions. Initially, behavior representative of a gaseous film is observed, followed by a region corresponding to liquid expanded film. Next, the isotherm shows a clear liquid expanded-liquid condensed phase transition region. Finally, a region containing only liquid condensed states is apparent. $n$-Alcohols produce weaker interactions on the asphaltene film. As a consequence, the adding of alcohols makes the films more compressible.
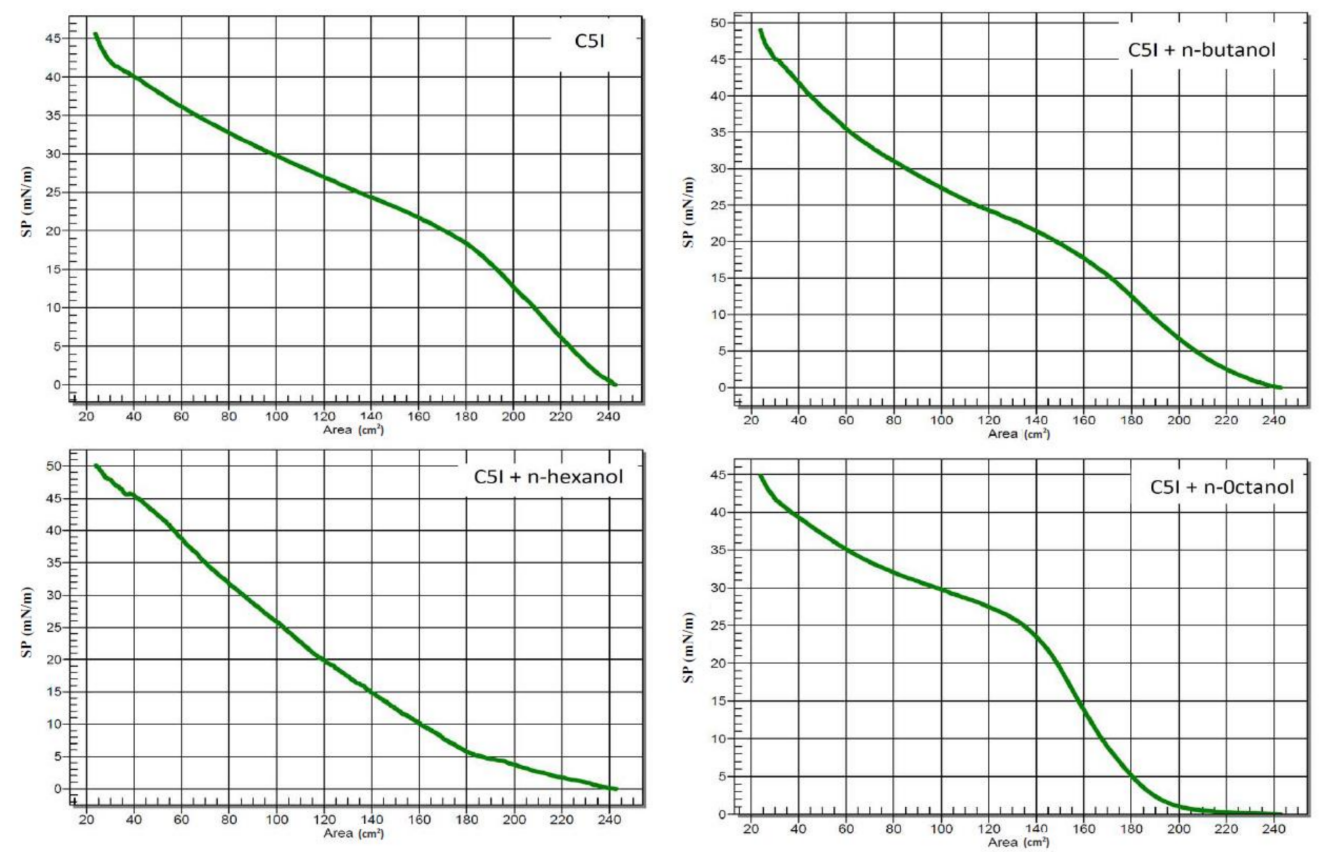

Figure 7. Langmuir isotherms $(\pi-\mathrm{A})$ for systems containing asphaltenes and different $n$-alcohols. SP: Surface Pressure. 


\section{Conclusions}

Surface/interface tension and surface pressure measurements highlight the influence of linear alcohols on the interfacial properties of crude oil asphaltene. $n$-Pentane asphaltenes extracted from a light oil displayed substantial self-aggregation behavior, verified by tensiometry and interfacial adsorption from surface pressure measurements. Asphaltene did not show an effective reduction in surface tension. $n$-Alcohols promoted a further reduction of the surface and interfacial tension of asphaltene solution. The presence of $n$-alcohols lead to more compressible asphaltene films. It has been reported that oil/water interfacial tension [14] and interfacial film elasticity [11] both regulate key emulsion properties such as stability. In this way, the present results could be useful in the design of crude oil-in-water emulsions with appropriate stability, droplet size and viscosity, by way of adding suitable alcohols into the emulsion formulation. Finally, the results indicate the possibility of $n$-alcohol addition to emulsifying and demulsifying agents, respectively, to heavy oil pipelines and in water-in-oil breaking applications.

Acknowledgments: The authors gratefully acknowledge support from the São Paulo Research Foundation (FAPESP) by means of the Project 2013/25880-3.

Author Contributions: R.G. Santos was responsible for the experimental design, surface pressure measurements, data analysis and data report. R.G. Martins and L.S.M. contribute to the current research by sample preparation and performing surface and interfacial tension measurements.

Conflicts of Interest: The authors declare no conflicts of interest.

\section{References}

1. Speight, J.G. The Chemistry and Technology of Petroleum, 2nd ed.; Marcel Dekker, Inc.: New York, NY, USA, 1991.

2. Loh, W.; Mohamed, R.S.; Santos, R.G. Crude Oil Asphaltenes: Colloidal Aspects. In Encyclopedia of Surface and Colloid Science; Somasundaram, P., Ed.; Taylor \& Francis: New York, NY, USA, 2007; Volume 1, pp. 1-18.

3. Santos, R.G.; Loh, W.; Bannwart, A.; Trevisan, O. An overview of heavy oil properties and its recovery and transportation methods. Braz. J. Chem. Eng. 2014, 31, 571-590. [CrossRef]

4. Ovalles, C.; Garcia, M.D.; Lujano, E.; Aular, W.; Bermudez, R.; Cotte, E. Structure-interfacial activity relationships and thermal stability studies of Cerro Negro crude oil and its acid, basic and neutral fractons. Fuel 1998, 77, 121-126. [CrossRef]

5. Nenningsland, A.; Simon, S.; Sjoblom, J. Surface properties of basic components extracted from petroleum crude oil. Energy Fuels 2010, 24, 6501-6505. [CrossRef]

6. Ramos, A.C.S.; Haraguchi, L.H.; Notrispe, F.R.; Loh, W.; Mohamed, R.S. Interfacial and colloidal behavior of asphaltenes obtained from Brazilian crude oils. J. Pet. Sci. Eng. 2001, 32, 201-216. [CrossRef]

7. Sheu, E.Y. Petroleum asphaltenes-Properties, characterization, and issues. Energy Fuels 2002, 16, 74-82. [CrossRef]

8. Stephenson, K. Producing asphaltenic crude oils: Problems and solutions. Pet. Eng. Int. 1990, 8, $24-31$.

9. De Boer, R.B.; Leerlooyer, K.; Eigner, M.R.P.; van Berger, A.R.D. Screening of crude oils for asphalt precipitation: Theory, practice and the selection of inhibitors. Soc. Pet. Eng. 1992, 24987, 259-270. [CrossRef]

10. Mohamed, R.S.; Loh, W.; Ramos, A.C.S.; Delgado, C.C.; Almaeida, V.R. Reversibility and inhibition of asphaltene precipitation in Brazilian crude oils. Pet. Sci. Technol. 1999, 17, 877-896. [CrossRef]

11. Kabbach, C.B.; Santos, R.G. Effects of $\mathrm{pH}$ and temperature on the phase behavior and properties of asphaltene liquid films. Energy Fuels 2017. [CrossRef]

12. Oliveira, P.F.; Santos, I.C.V.M.; Vieira, H.V.P.; Fraga, A.K.; Mansur, C.R.E. Interfacial rheology of asphaltene emulsions in the presence of nanoemulsions based on a polyoxide surfactant and asphaltene dispersant. Fuel 2017, 193, 220-229. [CrossRef]

13. Langevin, D.; Poteau, S.; Hénaut, I.; Argillier, J.F. Crude oil emulsion properties and their application to heavy oil transportation. Oil Gas Sci. Technol. 2004, 59, 511-521. [CrossRef]

14. Santos, R.G.; Bannwart, A.C.; Loh, W. Phase segregation, shear thinning and rheological behavior of crude oil-in-water emulsions. Chem. Eng. Res. Des. 2014, 92, 1629-1636. [CrossRef] 
15. Salager, J.L.; Briceño, M.I.; Brancho, C.L. Heavy hydrocarbon emulsions. In Encyclopedic Handbook of Emulsion Technology; Sjöblom, J., Ed.; Marcel Dekker: New York, NY, USA, 2001.

16. Santos, R.G.; Briceño, M.I.; Bannwart, A.C.; Loh, W. Physico-chemical properties of heavy crude oil-in-water emulsions stabilized by mixtures of ionic and non-ionic ethoxylated nonylphenol surfactants and medium chain alcohols. Chem. Eng. Res. Des. 2011, 89, 957-967. [CrossRef]

17. Graciaa, A.; Lachaise, J.; Cucuphat, C.; Bourrel, M.; Salager, J.L. Improving solubilization in microemulsions with additives. 2. Long chain alcohols as lipophilic linkers. Langmuir 1993, 9, 3371-3374.

18. Bourrel, M.; Chambu, C. The rules for achieving high solubilization of brine and oil by amphiphilic molecules. Soc. Pet. Eng. J. 1983, 23, 327-338. [CrossRef]

19. Ross, S. The Change of Surface Tension with Time. I. Theories of Diffusion to the Surface. J. Am. Chem. Soc. 1945, 67, 990-994.

20. Firooz, A.; Chen, P. Surface tension and adsorption kinetics of amphiphiles in aqueous solutions: The role of carbon chain length and temperature. J. Colloid Interface Sci. 2012, 370, 183-191. [CrossRef] [PubMed]

21. Nordli, K.G.; Sjoblom, J.; Kizling, J.; Stenius, P. Water-in-crude oil-emulsions from the Norwegian continental-shelf. 4. Monolayer properties of the interfacially active crude-oil fraction. Colloids Surf. 1991, 57, 83-98. [CrossRef]

22. Poteau, S.; Argillier, J.; Langevin, D.; Pincet, F.; Perez, E. Influence of pH on Stability and dynamic properties of asphaltenes and other amphiphilic molecules at the oil-water interface. Energy Fuels 2005, 19, 1337-1341. [CrossRef]

23. Vieira, V.C.C.; Severino, D.; Oliveira, O.N.; Pavinatto, F.J.; Zaniquelli, M.E.D.; Ramos, A.P.; Baptista, M.S. Langmuir films of petroleum at the air-water interface. Langmuir 2009, 25, 12585-12590. [CrossRef] [PubMed]

(C) 2018 by the authors. Licensee MDPI, Basel, Switzerland. This article is an open access article distributed under the terms and conditions of the Creative Commons Attribution (CC BY) license (http:/ / creativecommons.org/licenses/by/4.0/). 